\title{
Sistema para auxiliar pessoas com deficiência visual no reconhecimento de cédulas de dinheiro em Real com a técnica de Redes Neurais Artificiais
}

Fabrício Samuel Sausen, Rejane Frozza

\author{
Universidade de Santa Cruz do Sul (UNISC) \\ Departamento de Engenharias, Arquitetura e Computação \\ Curso de Ciência da Computação \\ Av. Independência, 2293 - 96815-900 - Santa Cruz do Sul, RS \\ fabriciosausen@mx2.unisc.br, frozza@unisc.br
}

\begin{abstract}
Resumo. A deficiência visual afeta um grande número de pessoas no Brasil. Segundo o Censo Demográfico realizado em 2010, pelo Instituto Brasileiro de Geografia e Estatística (IBGE), cerca de 3,4\% da população brasileira possui deficiência visual, ou seja, cerca de 443 mil pessoas. Dentre os diversos problemas enfrentados por elas, destaca-se o uso do dinheiro, para o qual dependem do auxílio de pessoas conhecidas para realizar a identificação das cédulas. Neste sentido, este trabalho, ainda em andamento, busca desenvolver um sistema que as auxilie no reconhecimento de cédulas de dinheiro em Real, através de um aplicativo para smartphones, utilizando-se de técnicas de Redes Neurais Artificiais.
\end{abstract}

\begin{abstract}
Visual impairment affects a large number of people in Brazil. According to the Demographic Census in 2010, by the Brazilian Institite of Geography and Statistics (IBGE), about 3,4\% of the Brazilian population has visual impairment, that is, about 443 thousand people. Among all problems faced by them, we stand out the use of money, in which they are dependant on the help from known people to identify the banknotes. In this sense, this work seeks to develop a system to assist them in the recognition of the Real banknotes, through and application for smartphones, using Artificial Neural Networks techniques.
\end{abstract}

\section{Introdução}

O número de pessoas com algum tipo de deficiência no Brasil é grande. Segundo dados do Censo Demográfico de 2010, coletados pelo Instituto Brasileiro de Geografia e Estatística - IBGE, do total da população brasileira, em média $6,7 \%$ ou 12,7 milhões de pessoas declaram ter algum tipo de deficiência. Dentre as deficiências declaradas, a mais comum mostrou-se ser a deficiência visual, atingindo $3,4 \%$ da população brasileira, ou seja, cerca de 443.454 pessoas (IBGE, 2018).

Dentre as dificuldades enfrentadas por pessoas com deficiência visual, destacase a dependência. Pelo fato de não enxergarem, a locomoção, o trabalho e a identificação de objetos são atividades complicadas de serem realizadas de forma independente. Esta última, a identificação de objetos, engloba diversos aspectos do 
cotidiano de uma pessoa inserida em sociedade, como por exemplo, a identificação e uso de dinheiro.

Em muitos casos, a identificação e, consequentemente, o uso do dinheiro ainda é um desafio para pessoas com deficiência visual, pois dependem de auxílio de pessoas conhecidas na contagem e separação do dinheiro, bem como da boa vontade e das virtudes de cada cidadão para não serem enganados, ao receber $\mathrm{o}$ troco $\mathrm{em}$ estabelecimentos comerciais em geral, por exemplo.

Visando tornar mais independente a vida de pessoas com deficiência visual, este trabalho propõe o desenvolvimento de um sistema computacional capaz de reconhecer cédulas de dinheiro em Real, de forma automática, através de um smartphone. Para tornar isto possível, é proposto o uso de Aprendizado de Máquina (AM), mais especificamente, a técnica de Redes Neurais Artificiais (RNAs).

Neste contexto, o problema de pesquisa refere-se a: Como a identificação de cédulas de dinheiro em Real, com o uso da técnica de Redes Neurais Artificiais, pode auxiliar pessoas com deficiência visual? Acredita-se que, com o auxílio de um sistema, é possível auxiliar pessoas com deficiência visual a separar ou contar o dinheiro em certos momentos, como: i) antes de sair de casa; ii) ao/após receber um pagamento; iii) ao/após receber um troco; iv) ao realizar um pagamento.

O artigo está organizado nas seguintes seções: a seção 2 apresenta uma breve fundamentação teórica, a seção 3 descreve a metodologia, na seção 4 são abordados os aspectos referentes à proposta do trabalho e a seção 5 apresenta as considerações finais.

\section{Fundamentação Teórica}

O Aprendizado de Máquina (AM) é uma vertente da área de Inteligência Artificial (IA), que procura, através de dados de entrada, desenvolver algoritmos capazes de aprendêlos e, assim, auxiliar na tomada de decisões, como: reconhecimento de padrões, previsão e detecção de anomalias/fraudes. Segundo Rezende (2003), “Aprendizado de Máquina é uma área de IA cujo objetivo é o desenvolvimento de técnicas computacionais sobre o aprendizado, bem como a construção de sistemas capazes de adquirir conhecimento de forma automática".

De forma geral, o AM pode ser dividido em cinco tipos: i) Aprendizado Supervisionado; ii) Aprendizado Não-Supervisionado; iii) Aprendizado SemiSupervisionado; iv) Aprendizado por Reforço; v) Aprendizado Profundo.

Segundo Pila (2001) "no aprendizado supervisionado o objetivo é extrair conhecimento de exemplos previamente rotulados com classes, a fim de predizer a qual classe pertencem novos exemplos". Portanto, pode-se imaginar o Aprendizado Supervisionado como um método que necessita de dados de entrada (exemplos) previamente rotulados, que serão utilizados para extração de conhecimento durante o processo de aprendizado de um modelo preditivo, capaz de classificar novos exemplos durante o processo de treinamento.

Já no Aprendizado Não-Supervisionado, não há informação prévia da classe ou rótulo de uma informação, apenas dos atributos que compõem os dados de entrada (exemplos). A Google (2019) cita que o uso mais comum de Aprendizado NãoSupervisionado é agrupar dados em grupos de exemplos similares. Assim, este método 
de aprendizagem é responsável por utilizar algoritmos que possuem o propósito de encontrar padrões em um conjunto de dados, tornando possível sua posterior separação em classes.

No Aprendizado Semi-Supervisionado, o conjunto de dados possui alguns dos exemplos já rotulados e outros não, ou seja, é uma mistura do Aprendizado Supervisionado e do Aprendizado Não-Supervisionado. Assim, pode ser útil quando rotular exemplos se torna dispendioso em termos de tempo ou dinheiro, mas os exemplos não rotulados forem abundantes (Google, 2019).

O Aprendizado por Reforço difere totalmente dos métodos descritos anteriormente, pois não há um conjunto de treinamento associado, ou exemplos rotulados. De acordo com Korbut (2017), aprendizado por reforço é uma área de AM que se preocupa com a forma com que os agentes de software, ou algoritmos, devem agir em determinados ambientes de modo a maximizar alguma noção de recompensa cumulativa.

Por fim, o Aprendizado Profundo é um método baseado em representações de dados, com várias camadas de neurônios de processamento, podendo utilizar algoritmos de aprendizagem supervisionada e não-supervisionada nas diferentes camadas (Sinha, Pandey e Pattnaik, 2018).

Uma das técnicas que se utiliza do Aprendizado de Máquina, utilizada no reconhecimento de padrões, são as Redes Neurais Artificiais, a qual o termo foi motivado pelo reconhecimento de que o cérebro humano opera de maneira completamente diferente de um computador digital convencional. $O$ cérebro tem a capacidade de organizar a estrutura que o constitui, conhecido como neurônios, de maneira a executar algumas tarefas, como: reconhecimento de padrões, percepção e controle motor muitas vezes mais rápido que os computadores mais rápidos hoje existentes (Haykin, 1999). De acordo com Haykin (1999), "Uma Rede Neural é um processador distribuído massivamente paralelo feito de simples unidades de processamento, que possuem uma propensão natural para guardar conhecimento de experiências e tornar isso disponível para uso.

O processo de aprendizado, ou algoritmo de aprendizado de uma RNA possui a função de ajustar os pesos sinápticos, a fim de que, após um número finito de iterações, a rede desempenhe um papel o mais próximo do objetivo proposto. Além disso, de acordo com Rezende (2003), considera-se que o processo de aprendizado tem como característica a ocorrência de estímulo da rede pelo meio externo através da apresentação do conjunto de dados.

\section{Metodologia}

Foi realizado um levantamento de publicações na área, relacionadas ao trabalho proposto, bem como a síntese de trabalhos relacionados para obtenção de conhecimento. O levantamento de publicações na área foi feita a partir de uma bibliometria quantitativa (Araújo, 2006) nas bases de dados Scopus e Science Direct, com filtro de período de 2015 a 2020 e com termos de busca: "patterns recognition", "banknote" e "machine learning". Na base Scopus a área de pesquisa foi Computer Science e o tipo de documento filtrado foi article, já na base Science Direct foi utilizado apenas o filtro de 
tipo de documento para review articles e research articles, por não possuir filtro de área específica.

Com a pesquisa realizada, obteve-se um resultado contendo 74 artigos na base Science Direct e apenas 1 artigo na base Scopus. A partir deste resultado, foram selecionados artigos relacionados com o tema de pesquisa deste trabalho. Dois deles foram encontrados na base Science Direct, com os três termos de busca combinados, e outro encontrado no Simpósio Brasileiro de Informática na Educação - SBIE, por se relacionar com o tema desta pesquisa. Os trabalhos são de: Doush e AL-Btoush (2017), Sarfraz (2015) e Mombach e Welfer (2013).

A partir dos estudos realizados e da análise dos trabalhos relacionados, foi possível observar que é possível utilizar diferentes técnicas para realizar o reconhecimento de cédulas monetárias (Sarfraz, 2015; Doush e Al-Btoush, 2017). Porém, o reconhecimento de cédulas por si só não é o todo, é de grande valia ressaltar a importância da inclusão do público alvo durante o desenvolvimento e validação do sistema, assim como feito em (Mombach e Welfer, 2013). Assim, este trabalho propõe que o público alvo tenha participação durante o processo de desenvolvimento do sistema/aplicativo, pois é de essencial importância para a validação dos resultados.

Os procedimentos metodológicos definidos são: i) levantamento bibliográfico, com estudos realizados para obter aprofundamento nos temas da pesquisa; ii) levantamento de trabalhos relacionados, elaborando sínteses e quadro comparativo; iii) definição de aspectos de implementação, como linguagem e plataformas, bem como a maneira em que os dados de entrada serão adquiridos, dados estes a serem utilizados para treinamento e teste da RNA; iv) definição da arquitetura da RNA para o desenvolvimento do modelo reconhecedor de cédulas de dinheiro em Real; v) desenvolvimento do aplicativo para smartphone e vi) validação do processo com usuários.

\section{Proposta de um sistema para auxiliar pessoas com deficiência visual no reconhecimento de cédulas de dinheiro em Real}

O uso do dinheiro é algo comum no cotidiano da maioria das pessoas, porém, é algo que se torna difícil de ser realizado de forma independente por pessoas com deficiência visual. No Brasil, há cerca de 443 mil pessoas que possuem deficiência visual, ou seja, que, em grande maioria, encontra dificuldade no manuseio de cédulas de dinheiro. Sabendo disto, surgiu a motivação para propor um sistema que as auxilie no reconhecimento de cédulas de dinheiro em Real, de forma a promover a independência no uso de cédulas e, consequentemente, a melhora na qualidade de vida, com o uso das Redes Neurais Artificiais. A Figura 1 apresenta o foco desta pesquisa.

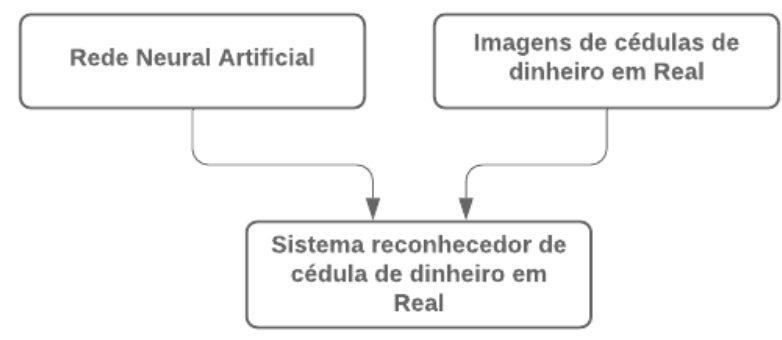

Figura 1 - Proposta da Pesquisa 
Uma conversa inicial ocorreu com um homem que possui deficiência visual. A Tabela 1 apresenta algumas questões importantes que foram discutidas de maneira informal durante a interação.

Tabela 1 - Resumo da interação com deficiente visual

\begin{tabular}{|c|c|}
\hline Questão levantada/discutida & Resumo da resposta informada \\
\hline $\begin{array}{lll}\text { Como você } & \text { realiza } & \text { o } \\
\text { reconhecimento das cédulas? }\end{array}$ & $\begin{array}{l}\text { "Separado em ordem na carteira, com ajuda de } \\
\text { alguma pessoa conhecida". }\end{array}$ \\
\hline $\begin{array}{l}\text { Em relação ao dinheiro, já passou } \\
\text { por alguma situação enganosa? }\end{array}$ & $\begin{array}{l}\text { "Sim, em tele entregas e mercado". Em adição, } \\
\text { informou que "se sente inseguro em qualquer } \\
\text { espaço que precise usar o dinheiro". }\end{array}$ \\
\hline $\begin{array}{l}\text { Seria interessante um aplicativo } \\
\text { que reconhecesse cédulas de } \\
\text { dinheiro? }\end{array}$ & "Sim, ajudaria bastante". \\
\hline Você usaria este aplicativo? & $\begin{array}{l}\text { "Sim, pois hoje dependo da ajuda de conhecidos } \\
\text { para separar o dinheiro". }\end{array}$ \\
\hline $\begin{array}{l}\text { Em sua visão, como o aplicativo } \\
\text { deveria funcionar? }\end{array}$ & $\begin{array}{l}\text { "- Identificação da cédula por áudio. } \\
\text { - Funcionar off-line. } \\
\text { - Dar alertas sobre o que o aplicativo está fazendo, } \\
\text { para situar o usuário". }\end{array}$ \\
\hline
\end{tabular}

O aplicativo reconhecedor de cédulas, a ser desenvolvido, levará em consideração questões de acessibilidade e aspectos mencionados na Tabela 1, como: funcionar off-line e com alertas sonoros em momentos específicos, como ao estar iniciando, para melhor situar o usuário. Para que tal aplicativo possa ser desenvolvido utilizando técnicas de Redes Neurais Artificiais, é necessária uma base de dados de imagens para cada um dos 7 tipos de cédulas, incluindo a nova cédula de 200 reais.

Considera-se uma base de 500 a 1000 imagens por tipo de cédula, suficiente para o treinamento de um modelo de RNA capaz de reconhecer e distinguir cada um dos tipos de cédulas. Sabendo-se da dificuldade de encontrar esta quantidade de imagens à disposição, foi desenvolvido um aplicativo auxiliar para tornar possível coletar e criar esta base de dados. Neste aplicativo, é possível tirar fotos e salvar em uma das 6 pastas configuráveis: notas_2, notas_5, notas_10, notas_20, notas_50 e notas_100. As notas de 200 reais serão capturadas de forma manual, por terem sido disponibilizadas há pouco tempo.

Além disso é possível configurar o aplicativo para capturar fotos em modo sequencial, com intervalo de 3 segundos, bem como utilizar o flash no momento da captura da foto.

\section{Considerações Finais}

A partir dos estudos realizados, pode-se constatar o grande número de pessoas com deficiência visual no Brasil e é preciso realizar pesquisas que possam trazer benefícios para a qualidade de vida destas pessoas e torná-las mais independentes na sociedade. Além disso, é possível observar que as Redes Neurais Artificiais, as quais possuem como uma das principais características o reconhecimento de padrões, são promissoras como solução para a proposta. 
Considerando os trabalhos relacionados, encontrados nas bases de dados pesquisadas, observou-se que os trabalhos vêm sendo desenvolvidos com intuito de auxiliar pessoas com deficiência visual no reconhecimento de imagens. Assim, para a próxima etapa deste trabalho, será desenvolvido um sistema para auxiliar pessoas com deficiência visual no reconhecimento de cédulas de dinheiro em Real, por meio de Rede Neural Artificial. Testes e validações serão realizadas no decorrer do desenvolvimento do sistema, a fim de avaliar o seu desempenho.

\section{Referências}

ARAÚJO, C. A. Bibliometria: evolução histórica e questões atuais. Em Questão, Porto Alegre, v. 12, n. 1, p. 11-32, 2006.

DOUSH, I. A.; AL-BTOUSH, S. Currency recognition using a smartphone: Comparison between color SIFT and gray scale SIFT algorithms. Journal of King Saud University - Computer and Information Sciences, Vol. 29, p. 494-492. 2017.

GOOGLE. Machine Learning Glossary, 2019. Disponível em: $<$ https://developers.google.com/machine-learning/glossary $>$. Acesso em: outubro 2019.

HAYKIN, Simon. Neural networks: a comprehensive foundation. Upper Saddle River: Prentice Hall, v. 2, 1999. 842 p.

IBGE - Instituto Brasileiro de Geografia e Estatística. Nota técnica 01/2018. Releitura dos dados de pessoas com deficiência no Censo Demográfico 2010 à luz das recomendações do Grupo de Washington. 2018. Disponível em: $<\mathrm{ftp}$ ://ftp.ibge.gov.br/Censos/Censo_Demografico_2010/metodologia/ notas_tecnicas/nota_tecnica_2018_01_censo2010.pdf $>$. Acessado em: outubro de 2019 .

KORBUT, Daniil. Machine Learning Algorithms: Which One to Choose for Your Problem. 2017. Disponível em: <https://statsbot.co/blog/machine-learningalgorithms/>. Acessado em: outubro de 2019.

MOMBACH, J. G.; WELFER, D. Proposta de um aplicativo móvel para percepção de imagens estáticas por alunos com deficiência visual. Brazilian Symposium on Computers in Education (Simpósio Brasileiro de Informática na Educação-SBIE). Vol. 24. No. 1. 2013.

PILA, Adriano Donizete. Seleção de atributos relevantes para aprendizado de máquina utilizando a abordagem de Rough Sets. 2001. Tese de Doutorado. Universidade de São Paulo.

REZENDE, Solange Oliveira. Sistemas Inteligentes - Fundamentos e Aplicações. São Paulo: Manole, 2003.

SARFRAZ, Muhammad. An intelligent paper currency recognition system. Procedia Computer Science. Vol. 65. 2015. p. 538-545.

SINHA, Rajat Kumar; PANDEY, Ruchi; PATTNAIK, Rohan. Deep learning for computer vision tasks: A review, 2018. 